\title{
ADVENTURES IN ACADEMIC CARTOGRAPHY: A MEMOIR
}

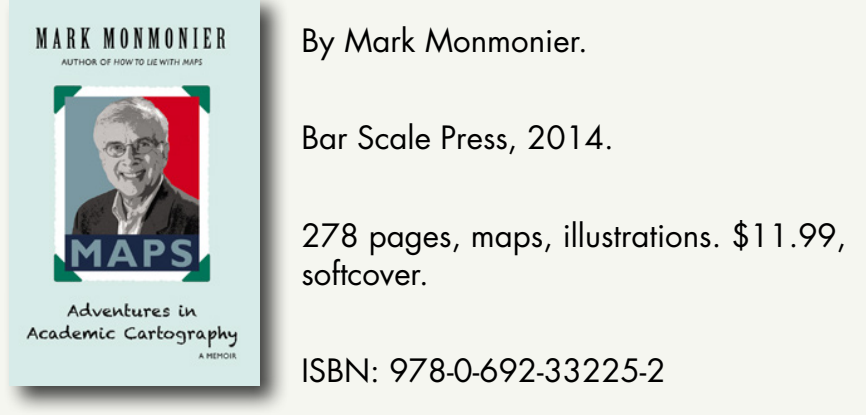

Review by: Leslie Wagner, The University of Texas at Arlington

Mark Monmonier's Adventures in Academic Cartography: $A$ Memoir takes the reader back to the beginning of Monmonier's career in academic cartography at a time of great change. He reflects on his budding interest in maps as a young boy and directs the reader through the swift evolution in academic cartography that took place during his lifetime. Monmonier has only a few years on me, and both having lived through eras of great change during the last century, I can say he has captured its essence. He reveals the choices that changed his life while he steered through and observed changes in the discipline. He relates his own adaptability in cartography and geography, taking us through the pursuit of his career and through the numerous obstacles and unexpected opportunities that his particular background afforded him.

By not adhering to a strict climb through the academic ranks, Monmonier blended his academic work with government contracting and consulting work in the private sector. In turn, this gave him a broader perspective which fueled the development of many new and practical applications in mapmaking. Monmonier takes us from the arduous methods of mid-twentieth century mapmaking to today's digital cartographic manifestations-and everything in-between - and in doing so gives us a dose of history in twentieth-century cartography.

A prolific writer, Monmonier delves into the subjects of his books, gives insight into his writing style and the world of publishing, and provides his take on the levels of success of each of his varied and diverse publications. He brings up the point that the intense research endeavors that culminated in his books also served to revive and transform his teaching. Although he merely inferred that it "informed my teaching," his enthusiasm for each project tells the reader otherwise. Monmonier discusses his contributions to cartographic literature, both academically and for the map-oriented layperson, along with the purpose behind each project. In his discussion of his post-9/11 and post-Hurricane Katrina efforts as part of the Mapping Science Committee (MSC), he injects his own political opinions and observations (here and elsewhere). His work with the MSC produced the federal government report, "Disaster Recovery Begins with a Map," which provides an excellent example of the relevance of new and continued applications of mapping in the real world. After all, how can one truly understand the magnitude of a disaster without its visual representation on a map?

During his career, he has also helped shape the field of academic cartography through his service on various committees and journals. His expertise boosted demand for his consulting work with clients among whom were most notably the US Geographical Survey and the National Geographic Society. Again, his broad approach to writing for an audience larger than academia increased demand for speaking engagements, which he juggled carefully with his continued role in academia.

\section{Mark Monmonier's Adventures in Academic Cartography: A} Memoir will appeal to anyone with an interest in cartography, geography, or just maps in general. Monmonier's writing style, which he also discusses in his chapter, "Writing," serves to carry the reader through the lesser thrills of his adventures, such as the blow-by-blow hits and misses of his publishing career, and projects that saw no fruition due to government red tape and budget cuts. Of his many successful projects, the ten-year project as editor of the recently published Cartography in the Twentieth Century (Volume 6 in the series, The History of Cartography), qualifies as a major achievement.

I found his chapter on writing particularly enlightening for those interested in writing and publishing. His advice, similar in my mind to that of Edgar Allen Poe, was to 
write with the end in mind. It boils down simply to knowing where you're going-what is the work's purposewhen you begin to write with any hope of publishing your work.

Monmonier speaks selectively on vintage maps and antiquities as he is, himself, a modest collector of maps. And he delves into a number of cartographic works from the past, adding his own opinion on the variety and type of collectors. I found the topic of collecting particularly appealing as well, in that I have my own meager selection of maps based on their content and relevance to my own research and interests.

All in all, Monmonier's Memoir has touches of humor and plenty of respect for his cartographic colleagues and their work. Readers can appreciate his viewpoint all the more because his publications were written to appeal to the general map-loving public. While his Memoir may be of greater interest to the academic crowd, there is still plenty for those of us who are simply map aficionados. More importantly, in all his efforts, he educates not only academia, but also the general public, in how maps are and can be used to convey ideas, to sway opinion, and even to fool the beholder. So if you still take a map at face value, look again, and read Mark Monmonier's Adventures in Academic Cartography: A Memoir, to follow his exploits in the world of maps. And when you're done with his Memoir, you will certainly want to take the journey through How to Lie with Maps. You'll never look at a map the same way again.
DESIGNING

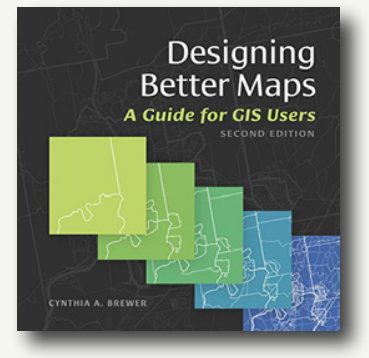

\section{BETTER MAPS:}

By Cynthia Brewer.

Esri Press, 2015.

231 pages, with maps and other figures throughout. $\$ 59.99$, softcover.

ISBN: 978-1-58948-440-5

\section{Review by: Amanda Tickner}

The author of Designing Better Maps: A Guide for GIS Users is Cynthia Brewer, who co-created the popular web resource ColorBrewer, a valuable tool that has been well-regarded for over a decade. She is a Professor and Head of the Department of Geography at The Pennsylvania State University. Clearly, someone well qualified to write a book on the subject of digital cartographic design.

The book addresses the importance of better map design in GIS. Courses in GIS often focus entirely on the analysis tools available and how to use them, rather than on the design of a map output. This book fills that potential gap.

The object of this book is to allow readers to gain an understanding of map design and graphic skills for effective mapmaking. It does so by taking a very fast and brief tour of many topics. Each chapter is introduced with a summary, and includes a bulleted list of major topics. This is a second edition, updates include a new discussion of

feature types and scale as well as improved illustrations (not changed in content but presented in a higher-resolution format).

The preface to the second edition is more interesting than most (usually these are not memorable, in my experience): it features a reflection on how digital mapping has changed over time from the author's perspective. Brief but insightful, it would make a nice longer essay.

Chapter One, "Planning Maps," reviews topics related to design essentials such as map purpose and hierarchy, white space, and layout, as well as the important topic of map projections. There is also discussion of how to solicit and respect critique from reviewers of your draft maps, which is a useful though non-technical aspect of mapmaking.

Chapter Two, "Base Map Basics," discusses map background options (such as elevation maps, imagery, vector features such as hydrology, and property boundaries), their appropriate scale, and techniques for production. There is more methodological information in this chapter with descriptions of methods within GIS used to create hillshades, etc., though these are not specific instructions nor are they particular to one software package.

Chapter 3, "Explaining Maps," covers the area of map elements including scale bars, grids, north arrows, legends, text placement, spacing, and hierarchies. There is a 